\title{
The use of PHC clinic-based women's groups for financial empowerment in a rural area
}

\author{
LR Uys, D Soc Sc \\ University of KwaZulu-Natal
}

BR Bhengu, PhD

University of KwaZulu-Natal

\author{
B Majumdar, PhD \\ McMaster University
}

\section{Keywords:}

Primary Health Care approach, economic empowerment, role of nurses, small business development

\section{Correspondence address:}

Prof LR Uys

School of Nursing

University of KwaZulu-Natal

Durban

4041

Tel: 0312608060

Fax: 0312601543

Email: uys@ukzn.ac.za

\section{Abstract: Curationis 29(1): 25-31}

The article is based on a four-year project during which Primary Health Care (PHC) nurses worked with women's groups in their areas. The aim of the study was to explore the involvement of PHC nurses in economic empowerment, both in terms of health promotion and in terms of the PHC approach. In particular the objectives were to establish whether nurses could lead economic empowerment groups, whether such groups could establish adequate external links and become financially viable. Eleven groups were used as case studies, and a cross-case analysis was done in terms of the three objectives. It was found that between the women and the nurses, adequate leadership existed for the groups to function well. Very limited external linkages were established, notwithstanding efforts in this regard. Nine out of 11 groups contributed to financial welfare of their members after 18 months, but a range of problems with regard to financial viability are identified.

\section{Acknowledgement}

The financial assistance of the Canadian International Development Agency for this project is gratefully acknowledged.

\section{Introduction}

The involvement of Community Health Nurses in community development is embedded in two movements. Firstly, the Primary Health Care approach, in which communities are encouraged to participate in solving their own problems (WHO, 1978:16). In poor communities this can never exclude economic empowerment, since poverty is always the first problem such communities identify when they participate in community projects (Raniga and Simpson, 2002: 85). Secondly it is a natural development from the health promotion movement, which emphasizes individuals and communities increase control over their own environment to improve their health (WHO, 1986: 426).

Community development is defined as the process of involving a community in the identification and reinforcement of those aspects of everyday life, culture and political activity which are conducive to health (Canadian Public Health Association, 1990:19). Community development involves empowerment, informed participation and ownership of development projects, which the Community Health Nurses are expected to facilitate (Swanepoel, 1997: 7).

According to Chalmers and Bramadat (1996:725) community development has 
increasingly become a significant part of the work of community health nurses, and a potentially valuable instrument in promoting health. The question is therefore, whether community health nurses could facilitate small business development as part of their community development work.

\section{Literature survey}

The Development Bank of Southern Africa (DBSA), in their 1991 report on the KwaZulu-Natal province, gave a participation rate in the labour market of $68 \%$ for Natal and $42 \%$ for KwaZulu, and unemployment rates of 11 and $18 \%$ respectively (Erasmus, 1991:23). In areas where unemployment is so high, economic empowerment and reduction of poverty is strongly related to job creation. There is substantial evidence to support the fact that rural women in South Africa are mostly neglected in development initiatives and policies (Gillward, 2002: 1). Oberhauser (1998:1) asserts that women's exclusion from many formal economic activities, especially in rural areas, has contributed to their involvement in casual or unregulated labour and income generating collectives as a means of coping with economic hardship. These activities, with the necessary support, Oberhauser (1998: 2) thinks, have the potential to empower these women. It would therefore seem that small business development should become a focus of most rural community development projects.

Small business development is only one of a number of strategies used for job creation (Organization for Economic Cooperation, 1992), which also includes housing developments, public works programmes, and transfer payments, such as unemployment benefits. A business that employs less than 50 people is considered to be a small business, while one employing less than 200 is seen as a medium business (Van Dijk, 1989: 8).

Krige's study (1987:14) in KwaMashu Township outside Durban showed that the highest percentage of small businesses is in sewing and knitting activities $(29 \%)$ and the average income was R209 per month. Hawking came second $(16 \%)$ and the average income for this group was R129 per month. Krige (1987:32) points out that most Black owned small businesses are at a subsistence level and do not create wealth. In a more recent survey, the Small
Business Unit (2001:8) of the University of Port Elizabeth found sewing to still be the most common activity, but chicken, and crop production also featured strongly. They found that between 8 and 10 people were usually involved, and each involved person supported an average of 7 people. They also identified a number of constraints on these businesses, such as locality, fencing, water, electricity, roads, premises, high transportation cost, access to finance and sanitation.

The Organization for Economic Cooperation (1992) highlights a long list of problems around economic development in rural areas. These include the small local markets, poor educational opportunities, loss of human resources due to urbanization, difficulty in establishing close contact and partnerships and problems around the exploitation of common property such as water and land. Other barriers to women's enterprises are that society, especially men, look down upon the women's goods. The lack of financial resources to purchase equipment and materials is another problem. These problems compel women to sell their goods from house to house or in the streets while they should be producing more (Sosibo, 1999: 2).

\section{Objectives and method of the study}

This project was launched to develop a model for community health nurses in PHC settings to become involved in health promotion outreach in their communities, through establishing and working with women's groups.

The specific questions asked in terms of the economic empowerment component were:

1. Can nurses successfully facilitate small businesses in established women's groups?

2. Can such groups establish the necessary external linkages to enable them to function?

3. Can such groups become financially viable?

\section{Methodology}

Case studies were done on each of the twelve groups that received funding from the project. In each case data was collected by doing a site visit, interviewing the groups of women, and looking at their financial statements and meeting records as well as inspection of their produce such as sewn items, vegetable gardens, chickens, etc. A template for the case study was used, which included both process and outcome. The template identified the source of information, for example, observation, record review or group interview (Yin, 2003: 67).

\section{Reliability and validity}

Reliability and validity were established using the relevant case study tactics as suggested by Yin (2003:34), for example: Three sources of evidence were used, namely, group interviews, record review and observation after which convergence of the information from these sources was determined in an attempt to ensure construct validity by triangulation. A detailed description of the sequence of events of each case was documented and the report was given to the key informants of the groups to review and verify.

\section{Project description}

Between 1998 and 2002 an empowerment project for rural women was run in the Northern region of Kwa-Zulu-Natal, the Zululand District. The project was facilitated by three partners (Schools of Nursing of the University of KwaZuluNatal and McMaster University in Canada, and the District Health authorities of the area) and funded by the Canadian International Development Agency (CIDA). (Uys, Majumbar \& Gwele, 2000:192).

The project consisted of, training nurses from Primary Health Clinics to run empowerment groups for women in their area, and work through a formal curriculum with them. The training took two days, and focused mainly on the philosophy and methods of peer or adult teaching, involving learners in learning and health promotion. The nurses each received a teaching guide setting out the content to be taught and the methods to be followed for each topic. They also received a flip chart of visual aids which they used to introduce topics and discussions.

The curriculum covered a wide range of topics, namely:

-
domestic violence and how to
deal with it,
how to access social




\begin{tabular}{|l|l|l|l|}
\hline $\mathbf{N r}$ & Group & Health service & Activity \\
\hline 1 & Siyathuthuka & Dengeni clinic & Sewing: machines and overlocker \\
\hline 2 & Siyasukuma & Kwamame clinic & Chicken rearing: building material for chicken houses \\
\hline 3 & Lethukuthula & Sizana clinic & Sewing: machines and overlocker \\
\hline 4 & Sukuma & Nkonjeni Hospital & Chicken rearing: building material for chicken houses \\
\hline 5 & Thuluzobona & Siyakhathala clinic & Gardening \\
\hline 6 & Ishelejuba & Itshelejuba hospital & Candle making \\
\hline 7 & Thubelihle & Ngqeku clinic & Chicken rearing \\
\hline 8 & Thandukuznezela & Tolakele clinic & Gardening \\
\hline 9 & Siziphembele & Idlebe clinic & Sewing: Machines and overlocker \\
\hline 10 & Msawenkozi & Friesgewacht clinic & Gardening: \\
\hline 11 & Daluxolo & Hartland clinic & Cellphone renting \\
\hline
\end{tabular}

assistance,

- $\quad$ promoting a good education for children,

- $\quad$ promoting health of self and family,

- $\quad$ caring for a family member who is ill,

- Income generation.

Over the first two years of the implementation of the project 82 nurses trained 565 women in 38 groups, at clinics and rural hospitals in the region. On average, groups of women had 13 members and they maintained an attendance rate of $76 \%$ over the total period of training. The work was supervised and supported by an experienced community health nurse, who had a project vehicle. She was seconded to the project by the Department of Health.

The last module dealt with economic empowerment through the following topics:

\section{- Establishing a formal organization \\ - Developing a business plan \\ - Keeping financial records \\ - Writing funding proposals}

An economic exhibition was held in Vryheid, where different government Departments, financial institutions, nongovernmental organizations and individual entrepreneurs exhibited at stalls which gave women ideas of what they could do and where they could go for help. Two women and a nurse from each group attended. Groups were then invited to submit funding proposals, accompanied by a business plan to the Project Committee. Based on their submissions, 11 groups involving 180 women were funded to launch small income generation projects. On average the groups got R10000 each, which was paid into the group's bank account after they had signed an agreement with the project. The agreement stipulated what they could use the money for and their reporting responsibilities. They were not expected to pay any money back.

\section{Sample description}

Table 1 sets out the groups, the associated health service and what they were funded for. The groups did not all get their money at the same time, since some had to submit their documents more than once.

\section{Ethical considerations}

Permission was sought from the Provincial Department of Health, District Health Officer in Ulundi, respective SubDistrict Health Officers, local Amakhosi, and the women, after the presentation and explanation of the research process and its implications. The interviews were tape recorded with permission from the participating women. The women were made aware of the option to opt out of the interviews at any time. Pseudonyms were used for the participating women.

\section{Data analysis}

Data from each group as a case was analyzed qualitatively after which cross case analysis was done to establish how the groups compared in as far as the set objectives of the study were concerned.

\section{Results}

Four groups will be described in detail to give insight into the work of some of the groups, and then the cross-case analysis will be presented. The groups chose different activities, in which three were reasonably successful, and one was not.

\section{Daluxolo group}

Site visit: Fourteen women attended the meeting. The Enrolled Nurse who ran this group was away doing the Bridging course to upgrade to a Registered Nurse. The chairperson of this group was not there, since she got a job in town. The secretary, Thulile, seemed to take the lead. She had all the documents with her, and answered most of the questions related to the phone business. The treasurer, Ntombi was there, and made hẹr contribution as well. The group met every Monday and Friday, and if it was necessary to meet in between, they sent messages with other people who lived in the area. A number of the women understood and spoke a little English.

This group got R 10000 from the project 
to start a Vodacom and a Telkom phone service in two different locations in their area. They were supposed to get a bank loan for another R10 000, but the bank demanded that they make their group smaller. They could not find any mechanism to exclude people, and therefore came to see the project committee to ask whether they could not give them R 16000 so that they could start the project on a smaller scale. This was agreed, and the money was paid into their account.

They had three businesses who supplied the Vodacom starter equipment. They got this information from different people. One was a woman who had such a business in Paulpietersburg, another was a nurse, and they also consulted other business people. Thulile phoned all three providers to get a final quote and compared prices. They planned to start the Vodacom business at Lubenjane, where three of the group lived. There was an old house there which they hoped to use. It used to belong to an agricultural officer, but there was no-one using it at the time. It had no doors or windows, but they were going to restore one room and use it. They thought there was a Vodacom signal there.

The Telkom line would be put into a spaza shop close to the clinic, where they were given permission to use the premises. The women close to the shop would staff this site. They planned to extend these two sites to others as soon as they had made enough money to pay for additional equipment.

Expenses: The Vodacom starter pack cost R6900 and then R1000 per month for six months. The Telkom line cost R1800 and then R200 per month. While we were there we went to Lubenjane to see whether there was a signal. There seemed to be one on a nearby hill, but not where the house was. They would investigate the possibility of getting a booster. They made this suggestion themselves. We also phoned all three companies. There was a significant difference in their rates, and the group would have to decide which one to take. They could get everything organized within one week.

While they waited for the phone business to go through, they started a garden at the clinic. We saw this garden, and it was quite impressive. They used the produce to make the R1000 which they used for their phone cost and going to town for the project, and also to open their bank account. They made contact with an agricultural officer based in Paulpietersburg, who worked for a company in Vryheid, and planted paprika for him. They had produced two bags which was ready for delivery. They also linked up with another group, to which Thulile's mother belonged, and sold chickens reared by this group. This was not successful, since they gave the customers credit, and they did not pay up. They then stopped that business.

\section{Final comments:}

This group subsequently ran three phones for rent. They were making income, and wanted to expand. This was difficult, since their income was limited, and they found it difficult to save for expansion.

\section{Itshelejuba group}

Site visit: This group used to consist of ten women, was reduced to five over time. One was ill that day, so only four were present for the visit. They had a hut on the hospital grounds where they kept their equipment. This hut was immaculately clean, and the two-plate stove, their molds, and other equipment were safely stored there. They also brought their toddlers with them, and they rested in the hut. The hospital administration was very supportive of the group, and asked them nothing for the use of the hut, the electricity and the phone. There were two registered nurses involved with this group, and they kept the documents, except for the bank book, which the women kept themselves.

The chairperson is Thembi, and she was present. When the researchers arrived the women were busy making mats from plastic sacking, plastic bags and wool, which were used for tables or floors. They sold these in their communities and made some money.

This group was approached by a salesman from a company that sells candle-making equipment. He donated a household candle making stand to them, and they bought the other equipment using the R10 000. They started the candle-making in February, and had bought two batches of wax from their grant. They made household candles, in different colours, and had also made a decorative type for which they had limited orders. However, the project was running at a loss. The wax was so expensive that they would have to sell an ordinary household candle for R6 to make a profit. Since these candles were sold for R 1 in the shops, this was clearly an impossible situation. They had been selling them for $\mathrm{R} 1$ to be competitive, and had paid all the money into their bank account. They had R3000 in their account, but the women had not been paid anything to date. They realized that they were working at a loss, and that is why half the members fell away. They wanted to do something other than candle-making, but they did not know what. They had quite a number of the decorative candles left, which they wanted to sell for R30 each, but they had no market for these. They had a small amount of wax left.

It was suggested to them that they make small Citronella candles which they could sell at R3 each and still make a profit, and which could be sold to tourists, but they were very demoralized, and did not have any contact with the tourist market. They were also encouraged to investigate the possibility of a garden in the hospital grounds. They would think this over.

\section{Final comments:}

This group was linked to a tourist centre at Pongola ( $20 \mathrm{Km}$ away) that provided meals, sold art and crafts, and gave out tourist information. The owner of this centre was willing to assist this group with selling the candles. They could get rid of the decorative candles there too, and would also provide a continuous market for the small citronella candles.

\section{Siyathuthuka group}

Site visit: Fourteen_women attended. They said that their goal was poverty alleviation, and they were grateful that they were making progress towards that goal. However, they wanted to expand the work to make more money. The chairperson, Gugu and the secretary, Busi were present and very active. The treasurer, Thandi, was also there, but very quiet. She had forgotten the bank book at home. Her voice had gone as a result of a cold. The nurse was not present during the interview, since the clinic was very short staffed. The women kept two books, with the one more or less listing expenditure, and the other income. They worked in one of the nurses' homes, which was not in use then.

This group got two electric sewing machines and an electric overlocker. 
Unfortunately, they still did not have electricity, although the researchers understood that they were the next community that would have electricity connected. It was not clear whether they asked for electric machines because they thought power would reach them sooner, or whether Lungi requested the wrong machines. They then preferred to keep the machines, which were being kept safely in the house of the nurse, waiting for the power to be switched on, although they were given the choice to change them for manual machines.

At the time they went to Durban to buy material for R500 and other necessities for R50. They spent R250 for transport for two people to Durban, R130 for food and R90 on phone calls. They went to Nongoma and bought one manual machine for R500, and since it did not work correctly, they went back to have it fixed. Transport cost them R120. They received their funds three months before the researchers came. They had bought two batches of material, and sold the products ( 14 garments from the first material). They were busy selling their second batch. They allowed people to take the garment if they had paid a $50 \%$ deposit. They then had a bit of difficulty getting the rest out of people, so they were not sure whether they were making a profit. However, they felt that if they did not allow people to take the garment, they would loose interest in buying it. They also stated that they did get all their money in the end.

They sold dresses for between R70 and $\mathrm{R} 100$ depending on the size and patterns, and they also made smaller items, such as aprons and skirts. They spent about an average of R39 to make a garment, and sold it, on average, for R51 making about $\mathrm{R} 12$ profit per garment. The problem was that they distributed the profit amongst 17 women, while only 4 did the sewing. That meant that they could pay each woman about $\mathrm{R} 18$ every three months, if they continued to sell one batch of garments every three months. Till then, they had paid each woman R50 in total, and some of this was earned before they got the funding. They had about R 1000 in their bank account, which they seldom used. They used the income from each batch of garments to pay for the next material. They were urged to buy a second hand machine, and to pay themselves R20 every three months. This was greeted with applause.
Before the funding came, they used to contribute R2 to R5 every time the group needed something, e.g. transport, or phone cost. This had stopped since the money came. They had also made themselves dresses out of the material they bought, but they had bought them at the market price.

Looking at the garments they made, their job was not professional. They knew this, and pointed out that they had not had training. They could not arrange for training before the electricity came, because a person could not come and give them training with only one machine. They had no quotations for training yet, since they could not proceed without adequate sewing machines.

The women felt that the income was not enough to make a difference to their lives. They also wanted to make mats, but had to have money to buy the material. They started had with a garden at the clinic a month before, but this was difficult, since there was no water at the clinic, so they had to fetch water from the river, which was far away. They also felt that this would not bring in much money, since most people had gardens at their own homes. (The researchers did not see such an abundance of gardens as they traveled through the area). The women's hope was fixed on when the electricity came, and they could get training, and be more productive, efficient and effective.

\section{Siyasukuma group}

Site visit: The researchers met with 11 women and one RN. There were 17 women in the group. They each paid a joining fee of R50, but this was increased to R150, when they realized that R50 was too little. They used this money to buy chickens and feed. This is the only group that sent us an extensive report, with full financial statement.

They used the R 10000 we gave them to buy building material and paid the bricklayer. They made mud blocks themselves, and built a three-roomed building, with chicken wire windows, sacking as curtains, and solid doors. It had a corrugated iron roof. They also used an existing, two-roomed building on the premises. These buildings were on the premises of the Roman Catholic Church, which was next to the clinic. They employed a night watchman at R140 per month. They had bought and raised 9 batches of chickens since the end of the previous year. They started with 150 per batch, but now they take 250 each time. The first three batches went very well, but then they lost many chickens in the following six batches. One reason was that the water feeder leaked on the chickens, and gave them hypothermia. Another lot got swollen heads and died ( 50 in one batch and 39 in another). The next batch died of white livers. They contacted the agricultural advisor, who said their hygiene was not adequate. In the next group only 2 chickens died. In the current batch, which was ready for sale, they had lost only 2 , but amongst the latest batch of chicks, they had already lost three.

In the beginning they all looked after the chickens, and when a chicken died, the person would report it but just throw it away. This was not good, so they decided to give every batch to three women, who looked after it exclusively. This worked much better.

The group sold the chickens for R21 each, and had no problem selling them. The sawdust they used on the floor was given to them free, but they had to pay for transport. They had not paid themselves anything during this time, and had only R272.31 in the bank. They could not work out their profit, and although they knew that they had been running at a loss since the fourth batch, they did not know how to reverse it.

On calculating their costs, the researchers realized that what was "eating" into their profit was the transport of feed and sawdust. They were paying somebody up to $\mathrm{R} 100$ to transport the sawdust and feed, and this could happen ten times for one batch of chickens, since the person brought only 8 bags of feed and 16 bags of sawdust at a time. Transport costs could therefore be as high as R1000 per batch. Another factor affecting their profit, was the death of chickens, but with experience they were, successfully, dealing with this problem.

The researchers worked out a plan which was dependent on the Siyasukuma group members keeping strictly to a budget plan for each batch of chickens.

\section{Final comments:}

By the end of the year this group was making money for the first time, and paid their workers R500 each. This was a major 
event for them, and they were going strong.

\section{Cross case analysis Leadership of nurses in facilitating projects}

Most of the nurses felt that they did not know enough about finance and business to assist the women in these activities. Their inability to understand even simple financial principles was evident during the site visits. Although most of the groups kept meticulous financial records, neither they nor the nurses could interpret the numbers. They could not calculate what their products cost them to produce, and could not identify why they were not making money.

In many cases the women themselves could manage the group. One nurse said in this regard, "This changed my mind. These women are smart. They can think better than I can". In terms of empowerment, the very lack of expertise of the nurses might be what made the women take charge as strongly as they had. According to Raniga and Simpson (2002:183) this is real community participation, and should be valued as such.

All the groups except one worked very responsibly with their money. They used it only for what the contract stipulated, and even when it took months for them to be able to buy the equipment, the money was kept safe. The one exception was a chicken rearing group who used the money for buying successive batches of chickens, which they reared at home, instead of using the money for building and fencing their chicken house. Because of unhygienic care, the chickens died, and they gradually used up all the money. The nurse in charge did nothing to stop this process. It is therefore evident that nurses lacked adequate business skills to facilitate the projects but women somehow made up by coping on their own.

\section{External linkage}

The groups used the following external resources: the agricultural officers from the Department of Agriculture, the banks, individual informants who had experience in specific businesses, and sales people. The organizer of the Economic Exhibition in Vryheid took the initiative to visit many of the groups and gave them additional training and support. For the most part, however, they were on their own.
The need for external support was evident in many of the groups. For instance, one group had money from the project executive for an electric pump to irrigate their garden. But since they knew nothing about electric pumps, they asked a farmer in the area to assist them in buying the pump. Four months later this farmer still had not had time to do this, and the group was still irrigating with buckets of water carried from the stream. The counter-productive influence of sales people was evident in the example of the Itshelejuba group described above.

The isolation and lack of knowledge and skills in these areas cannot be overemphasized. We could not find an NGO, Government supported initiative for poverty alleviation or business development with which to link the groups.

\section{Financial viability}

One year after the first project was funded; most of the groups had not taken any money to pay them-selves. It took about 18 months before the first group began to generate funds. The sewing, gardening, and telephone projects seemed to do best. The chicken rearing projects did well when they established the essential infrastructure and became disciplined in the management of the business. Nine of the eleven groups were already contributing to the income of the women at the time of writing the report.

The barriers to establishing the businesses on a financially viable basis seem to be the following:

1. Lack of understanding of financial principles, leading to poor business practices, poor pricing of products, and inability to stop bleeding from the business.

2. Too many women per group, which made financial and other control difficult and the income of each woman too small.

3. In gardening businesses, food was often given away to needy people. Although this limited the generation of income, the women felt that this was not a problem, since it was necessary that they helped others, and it made them feel less helpless and more powerful.

4. They found it too expensive to use financial services like banks. It cost a lot of money to go to town to withdraw or deposit money. The one group therefore withdrew the whole $\mathrm{R} 10000$ and was keeping it in a shoe-box in the house of the treasurer. Although they realized this was dangerous, they felt that paying $R 28$ every time they had to access the money was too much.

5. Some sewing groups had bought electric sewing machines even though they still had no electricity in their areas. They had all been promised electricity, and did not want machines that would be out of date within a year or so. In the one group the electricity became available a month before the site visit, but in another they were still waiting. Lack of skills was a problem in some groups. For instance, in one sewing group only one woman could cut out the garments. If she was not available, the group could not work. No training was available, nor could they afford it.

7. Transport cost was a major problem. This was taxing on the gardening projects, which needed to bring fencing, fertilizers and other equipment in, as well as for the chicken rearing projects. It would be ideal for the groups to organize themselves into cooperatives so that they could share transport costs, but this is a long way into the future.

\section{Discussion}

This model of community development has a number of strengths: It uses the nurses who are already widely dispersed in the rural areas, and are respected members of the community. It builds on the accepted role of nurses to promote health and prevent illness. It addresses the comprehensive development needs of the women, and is not narrowly focused on either health of economics or human rights. It allows women to get support from the existing infrastructure of the clinic during the development phases of the group. It gives women a neutral and safe place to meet and work. According to Chalmers and Bramadat's classification (1996: 723), this project used an empowerment model of community development, rather than an 
economic, or educational approach, although both of these are included in the intervention.

However, there are also a number of draw backs. In many of the groups attention is on their businesses and aspects of health promotion are getting little attention. Mogotlane and Uys (2000:23 and 2001: 17) found that groups which focused only on health issues had a definite impact on health indicators, while economically focused ones did not. Combining the two foci as was done in this project may endanger the health objectives.

The finding that it takes about 18 months for people to earn an income is consistent with the findings of Uys, Phillips and Zulu (1997: 38) in their work with disabled people. The barriers found to small business development in these areas are also consistent with those described by the Small Business Unit (2001:9-10), for example, poor infrastructure, financial constraints, market constraints and inadequate training in business management practice. Their recommendations, such as a functional network should be established to support these groups, are especially relevant.

\section{Conclusion}

The project has enabled women to come together in strong and enduring groups, which allowed women to negotiate an improvement in their positions at home and in the community. A group of women has emerged in these communities who act as a resource for other women with regard to social issues, health care and economic empowerment.

It has also built a core of economically active women who can potentially make a difference to their family's income. The partnership between the Primary Health Care nurses and the local women has been strengthened.

\section{References}

CANADIAN PUBLIC HEALTH ASSOCIATION 1990: Community health - public health nursing in Canada: preparation and practice. Ottawa: CPHA.

CHALMERS, KI \& BRAMADAT, IJ 1996: Community development: theoretical and practical issues for community health nursing in Canada. Journal of Advanced Nursing. 24(4): 719 -
26.

ERASMUS, J 1991: Economic and social memorandum, region E. Halfway House: Information Clearing House.

GILLWARD, C 2002: Deputy Minister for Justice and Constitutional Development: Access to Justice a vital contribution to the empowerment of women. An Address. http:// www.doj.gov.za/m_speeches/sp2002/ 2002_08_30.htm 1-5.

\section{KONGOLO,M \& BAMGOSE, O02002:}

Participation of Rural Women in Development: A Case Study of Tshseng, Thintwa and Makhalaneng Villages, South Africa. Journal of International Women's Studies. 4 (1) November 79-92.

KRIGE, DJ 1987: The prospect for informal small businesses in Kwamashu Durban: University of Natal.

MOGOTLANE, SM \& UYS, LR 2000: The function and impact of women's organisations on community development. Curationis, 23(1): 19-24.

MOGOTLANE, SM \& UYS, LR 2001:

The impact of women's organizations of health and community development. SA Family Practitioner. 22 (7): 13-17.

OBERHAUSER, AM 1998: Gendered Livelihood Strategies in Rural South Africa and Appalacia. A paper presented at Annual meeting of the South Eastern Division of the Association of American Geographers, Memphis.

ORGANIZATION FOR ECONOMIC COOPERATION 1992: Local initiatives for job creation: Businesses and jobs in the rural world. Paris: Organization for Economic Co-operation.

RANIGA, T \& SIMPSON, B 2002: Community participation: rhetoric or reality. Social Work. 38(2): 182-191.

RODWELL, CM 1996: An analysis of the concept of empowerment. Journal of Advanced Nursing. 23(2): 305-313.

SMALL BUSINESS UNIT 2001: Assessment of income generating activities in Region E, Eastern Cape. Kokstad: Bambisanani.

SOSIBO, Z 1999: Empowerment of Rural Zulu Women through Popular Adult Education in South Africa: A Case Study of the National Association for Women's Empowerment (NAWE) Program in KwaZulu-Natal. http:// www.edst.educ.ubc.ca/aerc/1999/ 99sosibo.htm 1-6

SWANEPOEL, H 1997: Community Development: Putting plans into action. $3^{\text {rd }}$ edition. Cape Town: Juta \& CO, LTD.

UYS, LR; MAJUMBAR, B \& GWELE, NS 2004: The KwaZulu-Natal Health Promotion Model. Journal of Nursing Scholarship. 36(3):192-196.

UYS, LR; PHILLIPS, N \& ZULU, RN 1997: Vocational rehabilitation in rural South Africa. Psychiatric Rehabilitation Journal. 21(1):31-39.

YIN, RK 2003: Case Study Research: Design and Methods. 3rd Edition. London : Sage Publications.

VAN DIJK, E 1989: A strategy for small business dvelopment in a black rural area - with special reference to Lebowa. $\underline{\text { Small }}$ Business News May. 1989 : 8-10.

WORLD HEALTH ORGANIZATION 1978: Primary Health care : Report of the International Conference on Primary health care. WHO : Alma Ata.

WORLD HEALTH ORGANIZATION 1986: The Ottawa Charter for health promotion. Canadian Journal of Public Health. 77(6) : 425-430. 